\title{
SUBSÍDIOS PARA O TRABALHO COM O GÊNERO DISCURSIVO REDAÇÃO DO ENEM
}

Ivone Ferreira de Alcantara Oliveira ${ }^{1}$

\begin{abstract}
Resumo: O objetivo geral da pesquisa foi propor atividades que contribuam para o trabalho com o gênero discursivo redação do ENEM. Especificamente, apresentam-se: um projeto que possibilita ao aluno ampliar seus conhecimentos sobre possíveis temas atuais propícios à redação do ENEM e sugestões para apropriação de características típicas dessa redação, necessárias ao momento de produção. Metodologicamente, é uma pesquisa de cunho bibliográfico, teoricamente fundamentada na concepção bakhtiniana de linguagem e no conceito de gênero discursivo; em estudos sobre o gênero redação do ENEM; na concepção sociocognitiva da leitura e de produção escrita. Os resultados indicam a possibilidade de propostas que podem subsidiar o trabalho teoricamente bem fundamentado dos professores que preparam seus alunos para a redação do ENEM.
\end{abstract}

Palavras-chave: Redação do ENEM. Produção Escrita. Concepção bakhtiniana de linguagem. Ensino de Língua Portuguesa.

\section{SUBSIDIES FOR WORKING WITH THE DISCURSIVE GENRE OF ENEM WRITING}

\begin{abstract}
The general objective of this research was to develop proposals that contribute to the work with ENEM essay discourse genre writing test. Specifically, instructions for research activities that enable the students to expand their knowledge on current topics proposed on ENEM essay writing test and suggestions for students appropriate typical characteristics of this writing test, necessary at the time of production, are proposed. Methodologically, it is a bibliographic research, theoretically based on the bakhtinian conception of language and the concept of discursive genre; in studies on the discursive genre of ENEM essay writing test; in the socio-cognitive conception of reading and written production. It is concluded that these proposals can support the theoretically well-grounded work of teachers who prepares their students for the ENEM essay writing test.
\end{abstract}

Keywords: ENEM essay writing test. Written production. Bakhtinian conception of language. Portuguese Language Teaching.

1 Mestre em Linguística Aplicada pelo Programa de Pós-Graduação Strictu Senso em Linguística Aplicada da Universidade de Taubaté (UNITAU). E-mail: ivone.alcantara@hotmail.com. 


\section{Introdução}

Este artigo é um recorte de minha Dissertação de Mestrado em Linguística Aplicada (OLIVEIRA, 2020), cujo tema é o trabalho com o gênero discursivo redação do Exame Nacional do Ensino Médio - ENEM. Sabe-se que essa redação avalia os jovens por várias habilidades de produção escrita, incluindo uma proposta de intervenção relativa ao problema social tematizado na prova. Isso exige do estudante um repertório de conhecimentos variados para dialogar com o contexto sóciohistórico e com a temática da prova.

Sendo professora de Língua Portuguesa, de uma escola pública de Ensino Médio em tempo integral situada em uma cidade do interior do Estado de Rondônia, deparei-me com a necessidade de práticas para o desenvolvimento dos estudantes no que se refere à redação do ENEM. Muitos deles se mostram empenhados nas aulas de produção textual, por terem como meta alcançar uma boa nota na redação do ENEM, o que contribui muito para ingressar na universidade, por meio dos programas SISU (Sistema de Seleção Unificada) ou PROUNI (Programa Universidade para Todos), ambos do Ministério da Educação. No entanto, faltam subsídios metodológicos para preparação desses alunos nas propostas de livros didáticos, além da escassez de tempo dos professores para o preparo de materiais fundamentados teoricamente.

A coleção didática utilizada na minha escola apresenta boas contribuições para o trabalho com produção escrita, além do material didático fornecido pelo Programa de Ensino Médio Integral do Estado de Rondônia que também traz sequências didáticas interessantes para esse trabalho. No entanto, em ambos os casos, as propostas de atividades são insuficientes no tocante à ampliação do repertório sociocultural dos estudantes, aspecto fundamental para o necessário diálogo com a proposta de redação do ENEM. A vivência em sala de aula mostra a necessidade de práticas de leitura que ampliem o senso crítico e o conhecimento dos alunos a respeito das questões sociais da atualidade. Os alunos precisam desenvolver a percepção da realidade que os cerca e das principais questões sociais que estão repercutindo na atualidade, para assim, realizar a redação do ENEM da melhor maneira.

Mesmo com mais de dez anos de experiência com o ensino de produção escrita, com conhecimentos adquiridos de maneira intuitiva e por meio de estudos individuais, eu carecia de bases teóricas para sistematizar minha prática e para compartilhá-la com outros professores da Rede de Ensino que integro e que busca socializar as práticas pedagógicas bem sucedidas de seus professores.

Nesse contexto, o objetivo geral estabelecido para a pesquisa foi propor atividades que contribuam para o trabalho com o gênero discursivo redação do ENEM, em sala de aula. Especificamente, para este artigo, apresentam-se: um projeto que possibilita ao aluno ampliar seus conhecimentos sobre possíveis temas atuais propícios à redação do ENEM e sugestões de etapas para apropriação de características típicas dessa redação, necessárias ao momento de produção. Esses objetivos específicos contemplam as competências 2, 3 e 5 exigidas pela Cartilha do Participante do ENEM 2019 (BRASIL, 2019, p. 6), reproduzidas a seguir.

2 - Compreender a proposta de redação e aplicar conceitos das várias áreas de conhecimento para desenvolver o tema, dentro dos limites estruturais do texto dissertativoargumentativo em prosa.

3 - Selecionar, relacionar, organizar e interpretar informações, fatos, opiniões e argumentos em defesa de um ponto de vista.

5 - Elaborar proposta de intervenção para o problema abordado que respeite os direitos humanos. 
As outras duas competências (1 e 4) exigidas pela Cartilha do Participante do ENEM (BRASIL, 2019) referem-se ao domínio da modalidade escrita formal da língua portuguesa e ao conhecimento dos mecanismos linguísticos necessários para a construção da argumentação. Por necessidade de delimitação desta pesquisa, essas competências não serão abordadas na proposta de atividades aqui delineada.

A pesquisa fundamenta-se teoricamente na concepção bakhtiniana de linguagem e no conceito de gênero discursivo; em estudos sobre o gênero discursivo redação do ENEM; na concepção sociocognitiva da leitura e produção escrita. Toda a proposta de trabalho com a redação do ENEM, desenvolvida a partir dessa fundamentação teórica, considera as prescrições da Base Nacional Comum Curricular - BNCC (BRASIL, 2018) e da Cartilha do Participante do ENEM 2019 (BRASIL, 2019).

Metodologicamente, é uma pesquisa de caráter bibliográfico e qualitativo, tal como definem Lakatos e Marconi (1991) e Gil (2010), pois utiliza como fontes de pesquisa material já elaborado, constituído por livros e artigos científicos sobre os temas mencionados. Para tanto, o trabalho em tela examina qualitativamente a fundamentação teórica para extrair categorias que subsidiam a proposta de atividades para preparar os alunos para a redação do ENEM, como expõem as seções a seguir.

\section{$A$ redação do ENEM como um gênero discursivo}

Esta pesquisa assume a concepção enunciativo-discursiva de linguagem e de trabalho com leitura e produção escrita em sala de aula, baseada nos estudos do filósofo russo Bakhtin, para quem "Todos os diversos campos da atividade humana estão ligados ao uso da linguagem" (BAKHTIN, 2011, p. 261). Logo, é preciso entender que um enunciado nunca se encerra nele próprio; há sempre o fenômeno da interação verbal entre sujeitos e meio social, em relação dialógica.

Os enunciados orais ou escritos são realizações de gêneros discursivos (do discurso). Além da propriedade dialógica, são constituídos por conteúdo temático, estilo e construção composicional, ligados no todo do enunciado e determinados pelas especificidades de cada campo da comunicação (BAKHTIN, 2011). O conteúdo temático ou tema, é ideologicamente derterminado, no sentido de significar de acordo com os valores, ideologias, conceitos de um momento sociohistórico. O estilo é marca específica do gênero, e não marca individual de cada autor. Mesmo que as enunciações sejam diferentes, devido a seu conteúdo, volume ou construção composicional, "possuem, como unidades da comunicação discursiva, características estruturais comuns e, sobretudo, limites absolutamente precisos" (BAKHTIN 2011, p. 274 - 275). Por último, a construção composicional, refere-se à forma de dizer o conteúdo temático por meio de estrutura comunicativa e semiótica típica do gênero, seleção dos recursos lexicais, fraseológicos e gramaticais da língua (componente linguístico) e, ainda, dos recursos não verbais.

Todas essas escolhas, lembra LopesRossi (2012), ocorrem a partir das condições de produção, de circulação, de recepção e do propósito comunicativo do gênero (também denominados aspectos sociocomunicativos do gênero), bem como da apreciação valorativa do enunciador a respeito da temática em questão. Pela importância desse contexto sócio-histórico de produção de um gênero discursivo e das muitas possíveis relações dialógicas que se estabelecem a partir dele, é essencialmente importante considerá-lo no trabalho didático de produção escrita. Bakhtin (2011, p. 356) afirma "A palavra, viva, indissociável do convívio dialógico, por sua própria natureza quer ser ouvida e respondida". No caso desta pesquisa, impõe- 
se que as atividades didáticas de preparação para a redação do ENEM contemplem esses aspectos sociocomunicativos desse gênero e possibilitem o convívio dialógico dos alunos com os temas das propostas de redação. Responder dialogicamente a esses temas exige repertório de conhecimentos variados.

O ENEM solicita a produção de um texto dissertativo-argumentativo. Essa nomenclatura é relativa à tipologia textual clássica, que classifica textos como descritivos, narrativos, dissertativos e argumentativos. O tipo textual é entendido como uma categoria que caracteriza o funcionamento da estrutura interna da configuração textual, numa concepção estrutural de linguagem, baseada apenas na materialidade linguística, como explica LopesRossi (2012). Essa é uma perspectiva muito mais restrita do que a dos gêneros discursivos, que envolvem as dimensões do discurso, muito além da materialidade linguística.

$\mathrm{Na}$ perspectiva teórica desta pesquisa, entende-se que o ENEM usa a nomenclatura "dissertativo-argumentativo" por demandar do produtor textual as capacidades de dissertar e argumentar a respeito de um tema proposto e de apresentar uma proposta de intervenção. Apesar da nomenclatura, a redação do ENEM é um gênero discursivo. Paulinelli e Fortunato (2016) explicam que, como qualquer outro gênero discursivo, a redação do ENEM também surgiu num determinado momento sócio-histórico, para atender a demandas de um exame vestibular de âmbito nacional, e obedece a determinadas condições de produção e de circulação (no caso entre os corretores da prova) específicas da sua esfera comunicativa escolar. Essa redação participa da esfera escolar, e o espaço físico de sua produção é o local em que as provas são realizadas.

Com relação às outras dimensões constitutivas do gênero discursivo Redação do ENEM, o conteúdo temático refere-se aos temas voltados para questões de ordem política, econômica, social, cultural; assuntos atuais, polêmicos, relacionados ao exercício da cidadania. Logo, exige-se do candidato que acione seus conhecimentos de mundo e outros recursos em busca da compreensão do tema. A forma composicional define-se nos limites da organização do texto dissertativo-argumentativo, em torno de três a quatro parágrafos: a introdução (contextualização do tema e a tese a ser defendida), o desenvolvimento (argumentação constituída por argumentos que promovam a adesão à tese defendida) e a conclusão (a proposta de intervenção social), expõem Paulinelli e Fortunato (2016).

O estilo abrange pelo menos três aspectos: os discursivos, os textuais e os linguísticos. Os discursivos referem-se: à ancoragem, forma pela qual o autor se coloca diante do texto, seja de forma pessoal ou impessoal; ao gerenciamento das diferentes vozes que devem ficar claras com expressões como "segundo fulano...", "em consonância com...", "no ponto de vista de...," entre outras; e à modalização do discurso, atenuando ou acentuando uma determinada afirmação. Os aspectos textuais incluem: os mecanismos e recursos linguísticos que garantem a coesão e a coerência do texto e permitem a progressão temática; os organizadores textuais responsáveis por estruturar o texto ao estabelecer conexões entre suas partes. Os aspectos linguísticos abrangem as escolhas lexicais apropriadas à situação de comunicação, o registro formal, a utilização das convenções da escrita, entre outros.

Prado e Morato (2016) também discutem a consolidação da redação do ENEM como gênero discursivo e questionam o fato de as instruções do exame determiná-lo como um texto dissertativo-argumentativo. Segundo os autores, o estudante deve conhecer e praticar esse gênero discursivo a partir de todas as suas características sociocomunicativas e composicionais, e não apenas 
como uma estrutura argumentativa, que o prende dentro de regras e padrões pré-estabelecidos. Abrir espaço nas aulas de Língua Portuguesa que leve o aluno a praticar a escrita textual considerando as características sociocomunicativas do gênero discursivo, favorece a formação de estudantes escritores que demonstram autoria em seus textos.

Koch e Elias (2017) mostram que é possível tratar a argumentação na escrita em uma perspectiva dialógica. De acordo com as autoras, as pessoas são capazes de escrever textos que atendam aos seus objetivos e com adequação à situação prevista, se tiverem os conhecimentos linguísticos, de textos e de mundo e da situação sociocomunicativa em que os interlocutores estão envolvidos. Essas afirmações reforçam o direcionamento desta pesquisa quanto à importância da ampliação de conhecimentos dos alunos como ponto de partida da preparação para a redação do ENEM.

Com relação à situação sociocomunicativa, $\mathrm{A}$ Redação do ENEM 2019: Cartilha do participante (BRASIL, 2019) é um material que oferece informações importantíssimas ao candidato ao ENEM. Deve ser utilizado com os alunos, com ênfase nos critérios de avaliação da redaço. Entretanto, o professor precisa ter conhecimentos teórico-metodológicos para, a partir das orientações e sugestões apresentadas, elaborar procedimentos e propostas de atividades dialógicas, que levem em consideração as propriedades constitutivas do gênero discursivo Redação do ENEM. Para essa prática se realizar, também é necessário que o professor tenha subsídios teóricos para o trabalho com leitura e produção escrita.

\section{Leitura e produção escrita na abordagem sociocognitiva}

Assumo nesta pesquisa, de acordo com Lopes-Rossi (2018), que uma perspectiva sociocognitiva de leitura e produção escrita se combina muito bem com a perspectiva bakhtiniana de linguagem. Os principais pressupostos de toda essa fundamentação teórica podem ser didatizados.

Solé (1996) e Marcuschi (1999) explicam que a compreensão resulta da interação entre as informações textuais e os conhecimentos do leitor, num processo que gera inferências. Conforme Coscarelli (2002, p.11), "a compreensão de um texto escrito é o resultado da combinação de pelo menos duas fontes de informação: o texto e o conhecimento do leitor". Na busca da construção de significado, o leitor recorre aos seus esquemas mentais e os preenche de acordo com as informações contidas no texto. Contribui muito para esse processo o leitor ter objetivos de leitura, saber relacionar seus conhecimentos com as informações do texto, fazer inferências e monitorar continuamente sua compreensão. (SOLÉ, 1996). O trabalho didático proposto por esta pesquisa busca contemplar esses fatores essenciais à compreensão, tanto nas leituras para ampliação de conhecimentos sobre possíveis temas a serem contemplados pela redação do ENEM, quanto na leitura das propostas da redação dessa prova (enunciado e textos motivadores).

Nessa perspectiva, é preciso levar em conta que o texto não traz todos os sentidos explícitos, que o leitor "se coloca ativamente no processo interativo de geração de significados ao buscar a construção da compreensão de um texto" (VARGAS, 2015, p. 319). Diferentes leitores de um mesmo texto produzirão inferências distintas em decorrência de seus variados conhecimentos de mundo e variadas formas de interação com as informações do texto. Além disso, é necessário o monitoramento da leitura para que o leitor não extrapole o nível inferencial e passe a um nível de compreensão improvável ou impossível.

$\mathrm{Na}$ concepção sociocognitiva de leitura, a língua é abordada como "um fenômeno cultural, histórico, social e cognitivo que varia ao longo do 
tempo e de acordo com os falantes; ela se manifesta no uso e é sensível ao uso" (MARCUSCHI, 1996, p.71). Sendo a língua constituída por diversas significações e sentidos discursivos, um sistema estruturalista, restrito à superficialidade do texto, não é suficiente para compreendê-la. As atividades de leitura com os alunos devem se organizar a fim de que eles percebam a língua como um evento comunicativo e os exemplares de gêneros discursivos como ações que acontecem em contextos sociais, marcadas por interferências culturais e históricas.

Para esta pesquisa, interessa considerar essa perspectiva de leitura porque os alunos, nas atividades que visam ao desenvolvimento da argumentação exigida pela redação do ENEM, precisam ler muito. Essa leitura, portanto, precisa ser inferencial, com acionamento de conhecimentos prévios dos alunos sobre o tema e as características dos gêneros a que pertencem os textos, contextualizadas de forma que os alunos possam estabelecer relações dialógicas do texto com o contexto sócio-histórico atual, com contextos passados, com atitudes responsivas possíveis a partir daquela leitura.

$\mathrm{Na}$ proposta da redação do ENEM, são apresentados de três a cinco textos motivadores de gêneros diferenciados, com os quais o tema da redação dialoga e a partir dos quais o aluno deverá construir sua redação. Alguns desses textos apresentam imagens e aspectos gráficos. A compreensão dessa linguagem multissemiótica é inferencial e dialógica em níveis muitas vezes bastante complexos. Também precisa ser considerada no trabalho de preparação do aluno do Ensino Médio para a redação do ENEM. A leitura, assim, tem sido considerada dentro do escopo do multiletramento, que Rojo e Almeida (2012, p. 13) creditam às produções culturais letradas em efetiva circulação social, um conjunto de textos híbridos de diferentes letramentos, com os quais interagimos em diferentes produções culturais, e à multiplicidade de linguagens, modos ou semioses, presentes nos textos em circulação social, seja nos impressos, seja nos digitais.

Assim, a prática da leitura e produção escrita deve ir além dos conhecimentos que outrora eram o suficiente para o trabalho com a linguagem. O mundo globalizado abriu espaço para a multiplicidade de linguagens e semioses presentes nos textos em circulação social, o que provocou novos modos de leitura e novos perfis de leitores.

Isso deixa nítida a necessidade de se trabalhar, nas escolas, com práticas que envolvam os estudantes em novos e multiletramentos, também na produção escrita, que deixou de ser fortemente embasada nas regras gramaticais, como foi até a década de 70 do século XX, e passou a ser baseado em gêneros discursivos (LOPES-ROSSI, 2012). A esse respeito, Barbosa e Rovay (2012) também destacam o fato de os gêneros permitirem capturar tanto os aspectos estruturais presentes em um texto como os aspectos sócio-históricos e culturais, os quais são fundamentais para o processo de compreensão e produção de textos.

Bunzen (2006) explica que a pedagogia da diversidade entra em cena a partir dos anos 80, com os gêneros discursivos como objetos de ensino. Nessa perspectiva, ao se pensar no "trabalho com textos, outro conceito indissociável diz respeito aos gêneros em que eles se materializam, tomando-se como pilares seus aspectos temáticos, composicionais e estilísticos", esclarece Bunzen (2006, p.154-155). Justifica-se, então, o ponto de vista do autor, ao reforçar que as aulas de produção de textos devem ser compostas de atividades de leitura com foco na compreensão ativa e responsiva, na análise linguística e nos aspectos discursivos dos textos.

A proposta de Lopes-Rossi (2012) para o professor buscar a transposição didática de toda essa fundamentação, visando à produção de gêneros discursivos na escola, se organiza de forma que a primeira etapa seja toda voltada ao conhecimento 
do gênero, por meio da leitura de muitos exemplares e estudo de suas características. A segunda etapa se destina à produção, incluindo revisão e reescrita, seguindo as condições de produção típicas do gênero. A terceira etapa é dedicada à circulação da produção dos alunos, de acordo com a circulação daquele gênero na nossa sociedade.

Embora a sequência didática dessa autora ofereça vários recursos e orientações ao trabalho de leitura e escrita de gêneros discursivos, o processo de preparação do estudante para a redação do ENEM exige outros procedimentos pedagógicos que preparem o aluno para produzir um texto, no momento da prova, sem a possibilidade de consulta a outros materiais e sem a mediação do professor. As etapas de "Planejamento da produção (definição do assunto, esboço geral, forma de obtenção de informações, recursos necessários) e Coleta de informações” (LOPES-ROSSI, 2012, p. 239) terão que ser realizadas pelo estudante apenas com o recurso da memória, em busca de conhecimentos adquiridos no decorrer da sua formação estudantil e nas suas experiências de vida. Além disso, o estudante deverá dialogar com as questões sociais da atualidade que estejam relacionadas ao tema da prova do ENEM daquele ano. A lacuna nesses conhecimentos pode bloquear o estudante logo nas primeiras ações que ele deveria realizar para iniciar a escrita. Por isso, a sequência didática mencionada será ampliada e adaptada nesta pesquisa.

Sendo assim, o Projeto Atualidades, proposto na próxima seção, vai ao encontro dessa necessidade de preparar melhor o estudante para esse momento em que ele contará apenas com sua memória sobre os temas.

\section{Projeto Atualidades: preparação para a redação do ENEM}

O Projeto Atualidades é sugerido para ser desenvolvido nos dois primeiros bimestres do $3^{\circ}$ ano do Ensino Médio. Pretende-se incentivar os estudantes a ficarem atentos às questões sociais que mobilizam a atenção da sociedade ou mesmo daquelas que não estão recebendo atenção da mídia, mas são importantes para um grande contingente de brasileiros que sofrem de alguma maneira. As etapas a serem desenvolvidas se repetem nos dois bimestres (exceto a primeira, de apresentação do Projeto) trocando-se apenas os temas. A ideia é que os estudantes pesquisem e discutam vários temas, quanto maior for a quantidade de temas, possivelmente melhor será o aproveitamento dos alunos. Essa quantidade vai depender do número de aulas disponíveis para o Projeto, o que tem que ser resolvido por cada professor, de acordo com sua carga horária.

O quadro a seguir resume as quatro etapas de realização do projeto e os objetivos pretendidos em cada uma. 
Quadro 1: Projeto Atualidades: ampliando o repertório dos alunos sobre temas sociais

\begin{tabular}{l}
\hline Etapas \\
Primeira etapa: Apresentando a Redação do ENEM \\
e o Projeto Atualidades (realizada apenas uma vez): \\
a) Exposição sobre o que é a redação do ENEM, \\
com ênfase na temática e necessidade de uma \\
proposta de intervenção. \\
b) Apresentação do Projeto Atualidades: primeira \\
etapa de preparação para a redação do ENEM \\
c) Apresentação dos temas de redação dos ENEM \\
já realizados e comentários dos alunos sobre \\
seus conhecimentos a respeito dos temas. \\
Pergunta motivadora: Por que esse tema \\
envolve problemas de ordem social?
\end{tabular}

d) Organização dos alunos em grupos

Segunda etapa: conhecendo melhor os temas do

ENEM (realizada apenas uma vez):

a) Escolha, por cada grupo, de um dos temas de redação dos ENEM já realizados.

b) Pesquisas na internet sobre o tema (reportagens, entrevistas, vídeos, documentários) incluindo obrigatoriamente alguma foto, imagem, infográficos, charge.

c) Elaboração de um seminário para apresentação para a sala dos resultados da pesquisa.

d) Apresentação da proposta de intervenção que aquele grupo faria, no caso de uma redação sobre o tema e, se encontrar na internet, uma proposta de intervenção para o tema apresentada em alguma redação nota mil do ENEM. abjetivos pretendidos
Ampliar os conhecimentos dos alunos sobre os aspectos sociocomunicativos do gênero discursivo Redação do ENEM (condições de produção, de circulação, estilo, temática, inserção em um momento sócio-histórico e principais relações dialógicas que podem ser estabelecidas).

b) Alertar sobre a necessidade de conhecimentos amplos e variados sobre temas sociais relevantes na sociedade para construção da argumentação e proposta de intervenção exigida.

c) Mostrar exemplos de temas; motivar os alunos para começarem a prestar atenção a textos, reportagens, comentários de fontes diversas sobre temas dessa natureza.

d) Promover maior diálogo sobre os temas, nas etapas seguintes.

a) Propiciar a reflexão sobre os temas.

b) Oportunizar leitura inferencial dos textos pesquisados.

Oportunizar leitura de textos multissemióticos.

Estimular a atitude dialógica com as informações obtidas, com o contexto social dos alunos e com o contexto nacional, em uma perspectiva mais ampla.

c) Criar uma possibilidade de os alunos se expressarem oralmente, de forma organizada, e de organizarem apresentações em Power Point, por meio de sínteses e de recursos gráficos.

d) Finalizar a reflexão sobre os temas com a mesma exigência da redação do ENEM: proposta de intervenção que respeite os direitos humanos.

Terceira etapa: conhecendo melhor outros temas sociais da atualidade (repetida para cada tema estudado):

a) Escolha, por cada grupo, de um dos temas de uma nova relação de temas apresentada pelo(a) professor(as) e complementada com sugestões de temas pelos alunos.

b) Pesquisas na internet sobre o tema, (reportagens, entrevistas, vídeos, documentários) incluindo obrigatoriamente alguma foto, imagem, infográficos, charge.

c) Elaboração de um seminário para apresentação para a sala dos resultados da pesquisa.

d) Apresentação da proposta de intervenção que aquele grupo faria, no caso de uma redação sobre o tema.

Obs.: dependendo da disponibilidade de tempo, cada grupo pode escolher outro tema e repetir os procedimentos acima. Quarta etapa: avaliando o Projeto Atualidades

a) Avaliação dos resultados das pesquisas e das apresentações, envolvendo estudantes e professores (o professor de Língua Portuguesa pode ter convidado outros professores de áreas de conhecimentos relacionadas ao tema).

a) Fazer uma reflexão crítica sobre o trabalho, a participação dos alunos, a mediação do(s) professor(es), os problemas que podem ter atrapalhado o projeto, as sugestões para outras realizações desse Projeto.

Fonte: A própria autora. 
A adesão ao Projeto depende dos alunos entenderem a sua importância e sua relação com o desejo de realizarem uma ótima prova do ENEM. Por isso é importante uma exposição sobre o que é a redação do ENEM, o peso que ela tem na nota final do Exame e a ênfase que ela dá à temática social. Por fim, deve-se comentar como a necessidade de uma proposta de intervenção depende de muitos conhecimentos do aluno, pois ele terá que contar apenas com a memória na hora da prova. Sem que o professor utilize nomenclatura teórica, é importante que ele saiba que fundamentará seu trabalho no conceito de redação do ENEM como um gênero discursivo.

A apresentação dos temas de redação dos ENEM já realizados e comentários dos alunos sobre seus conhecimentos a respeito dessas temáticas é uma etapa importante da preparação. Esses temas não serão mais solicitados, no entanto, todos se referem a problemas sociais que mobilizam muitos conhecimentos de atualidades, de história, de geografia, sociologia, filosofia, matemática, biologia, de políticas públicas, entre outros. Envolvem questões éticas e ideológicas em discussão na sociedade há muito tempo. Uma conversa inicial, do tipo: quais assuntos os alunos menos conhecem, em quais nunca haviam pensado, quais acham que ainda são atuais, é muito importante nessa preparação que pretende ampliar o repertório sociocultural dos alunos.

Assim, recomenda-se o contato com os temas já solicitados pelo ENEM, de 1998 até 2019, listados a seguir. A conversa poderia começar com cada um dos temas em ordem cronológica, com a seguinte pergunta: Por que esse tema envolve(u) problemas de ordem social?

- 1998 - Viver e Aprender

- 1999 - Cidadania e participação social

- 2000 - Direitos da criança e do adolescente: como enfrentar esse desafio nacional
- 2001 - Desenvolvimento e preservação ambiental: como conciliar interesses em conflito?

- 2002 - O direito de votar: como fazer dessa conquista um meio para promover as transformações sociais que o Brasil necessita?

- 2003 - A violência na sociedade brasileira: como mudar as regras desse jogo

- 2004 - Como garantir a liberdade de informação e evitar abusos nos meios de comunicação

- 2005 - O trabalho infantil na realidade brasileira

- 2006 - O poder de transformação da leitura

- 2007 - O desafio de se conviver com a diferença

- 2008 - Como preservar a floresta Amazônica

- 2009 - O indivíduo frente à ética nacional

- 2010 - O trabalho na construção da dignidade humana

- 2011 - Viver em rede no século XXI: os limites entre o público e o privado

- 2012 - O movimento imigratório para o Brasil no século XXI

- 2013 - Efeitos da implantação da Lei Seca no Brasil

- 2014 - Publicidade infantil em questão no Brasil

- 2015 - A persistência da violência contra a mulher no Brasil

- 2016 - Caminhos para combater a intolerância religiosa no Brasil

- 2017 - Desafios para a formação educacional de surdos no Brasil

- 2018 - Manipulação do comportamento do usuário pelo controle de dados na internet

- 2019 - Democratização do acesso ao cinema no Brasil

Espera-se, nessa etapa, um levantamento de ideias sobre os temas, a partir da leitura dos textos de apoio da redação do ENEM para nortear a discussão das questões menos conhecidas pelos alunos. O objetivo é que esses estudantes abram suas perspectivas do que são temas sociais. Nesse 
momento, podem surgir comentários sobre outros assuntos sociais e atuais que poderiam ser solicitados numa redação do ENEM. Caso, isso ocorra, o professor, deve esclarecer que serão abordados em outro momento, e que dependerá da escolha de cada grupo. Pela natureza dessa etapa do Projeto, ela se realiza apenas uma vez.

Em seguida, passa-se à segunda etapa, com os alunos organizados em pequenos grupos, para que aprofundem seus conhecimentos sobre alguns desses temas que julgarem ainda pertinentes ao momento atual, possivelmente com novos aspectos em função de acontecimentos mais recentes. Para isso, cada grupo deve escolher um dos temas, fazer pesquisas na internet, buscando reportagens, entrevistas, vídeos, documentários, incluindo obrigatoriamente alguma foto, imagem, infográficos, charge para criar um contexto de leitura de textos multissemióticos. Espera-se que a compreensão envolva inferências, muito além da mera decodificação ou transcrição dos textos ou vídeos. A tarefa seguinte será a elaboração de um seminário para apresentação dos resultados da pesquisa, por meio de Power Point, cartazes, vídeos e resumos. Enfim, tais procedimentos visam a sintetizar as ideias principais e discussões a respeito dos temas pesquisados por cada grupo.

A pergunta motivadora da primeira etapa deverá se desmembrar em outras como: 1. Quais as principais informações sobre o tema, a partir da pesquisa do grupo? 2. Quem são os brasileiros prejudicados no contexto desse tema? 3. Onde vivem? 4. Quem são (se houver) os brasileiros que levam algum tipo de vantagem no contexto desse tema? 5. A que outras situações passadas e presentes da realidade brasileira esse tema está relacionado? 6. Qual a proposta de intervenção que o grupo faria, no caso de uma redação sobre o tema? 7. O grupo encontrou na internet uma proposta de intervenção para o tema apresentada em alguma redação nota mil do ENEM.
Toda a atividade estimula a atitude dialógica dos alunos, envolvendo tanto o contexto social deles, como o nacional, em uma perspectiva mais ampla. Espera-se, assim, que a atitude responsiva dialógica desses estudantes possa transpor para a sala de aula, e que percebam que os temas adquirem contornos diferentes, em função de uma série de fatores socioculturais.

Na sequência, parte-se para conhecer melhor outros temas sociais não abordados pelo ENEM, mas que poderiam sê-lo. A lista a seguir é uma sugestão que deve ser revista e reformulada a cada ano. Cada grupo de alunos deve escolher um dos temas:

- Desastre em Brumadinho e a gravidade da reincidência dos crimes ambientais

- A questão do desarmamento no Brasil

- Riscos do aumento do consumo de bebidas alcoólicas entre os jovens no Brasil

- A democratização do acesso à cultura no Brasil

- A tecnologia no combate à criminalidade

- O lixo e a sociedade de consumo no Brasil

- A população em situação de rua no Brasil

- Controle parental quanto ao uso da tecnologia: prevenção ou invasão à privacidade das crianças?

- A falta de acesso à cultura na sociedade brasileira

- A participação política do jovem no Brasil contemporâneo

- O aumento da taxa de criminalidade entre os jovens brasileiros

- A questão em torno da obrigatoriedade da vacinação no Brasil

- Caminhos para prevenir o suicídio entre os jovens no Brasil

- A igualdade de gênero no século XXI

- O papel da literatura na sociedade contemporânea

- A importância da educação financeira na vida do cidadão

- Os idosos na atual sociedade brasileira: valorizados ou negligenciados? 
- Desafios para o combate ao sedentarismo na sociedade brasileira

Os seminários poderão ser apresentados entre os próprios colegas da sala de aula ou por meio de eventos interclasses, envolvendo duas ou mais turmas e professores das disciplinas afins. Os participantes podem apresentar algumas indicações de obras literárias e filmes, para complementar repertório sociocultural sobre os temas. Dependendo da disponibilidade de tempo, cada grupo pode escolher outro tema e repetir esta etapa. Realizado esse Projeto Atualidades, espera-se que os alunos já tenham uma base de conhecimentos para iniciar as atividades de produção escrita de redações no formato do gênero discursivo Redação do ENEM, podendo então, dedicarem-se à apropriação das características e elementos típicos do gênero, tema tratado na próxima seção.

\section{A apropriação das características típicas da redação do ENEM para a produção escrita}

Considerando toda a fundamentação teórica apresentada, partimos do pressuposto que a produção escrita na escola é um processo que deve ser organizado em várias etapas, mediado pelo professor. Por meio da primeira etapa do Projeto Atualidades, exposto na seção anterior, espera-se que os alunos adquiram conhecimentos sobre os aspectos sociocomunicativos da redação do ENEM (condições de produção, de circulação, estilo, temática, inserção em um momento sóciohistórico e principais relações dialógicas que podem ser estabelecidas). Por meio da segunda e da terceira etapa desse Projeto, os alunos ampliam seu repertório sobre temáticas de cunho social. Até esse ponto do trabalho, houve ênfase nas competências 2, 3 e 5 exigidas pela Cartilha do Participante do ENEM (BRASIL, 2019) no que se refere à compreensão da proposta, ao desenvolvimento do tema e à proposta de intervenção. A competência 2 ainda contempla o conhecimento sobre os limites estruturais do texto dissertativo-argumentativo em prosa exigido pelo ENEM. Na sequência do trabalho de preparação dos alunos, portanto, é preciso focar nesse conhecimento. Em consonância com a perspectiva teórica desta pesquisa, são propostas atividades que mobilizam esse conjunto de conhecimentos necessários à produção escrita da redação do ENEM, como expõe o quadro 2 a seguir.

Quadro 2: Esquema geral para preparação de alunos para a Redação do ENEM

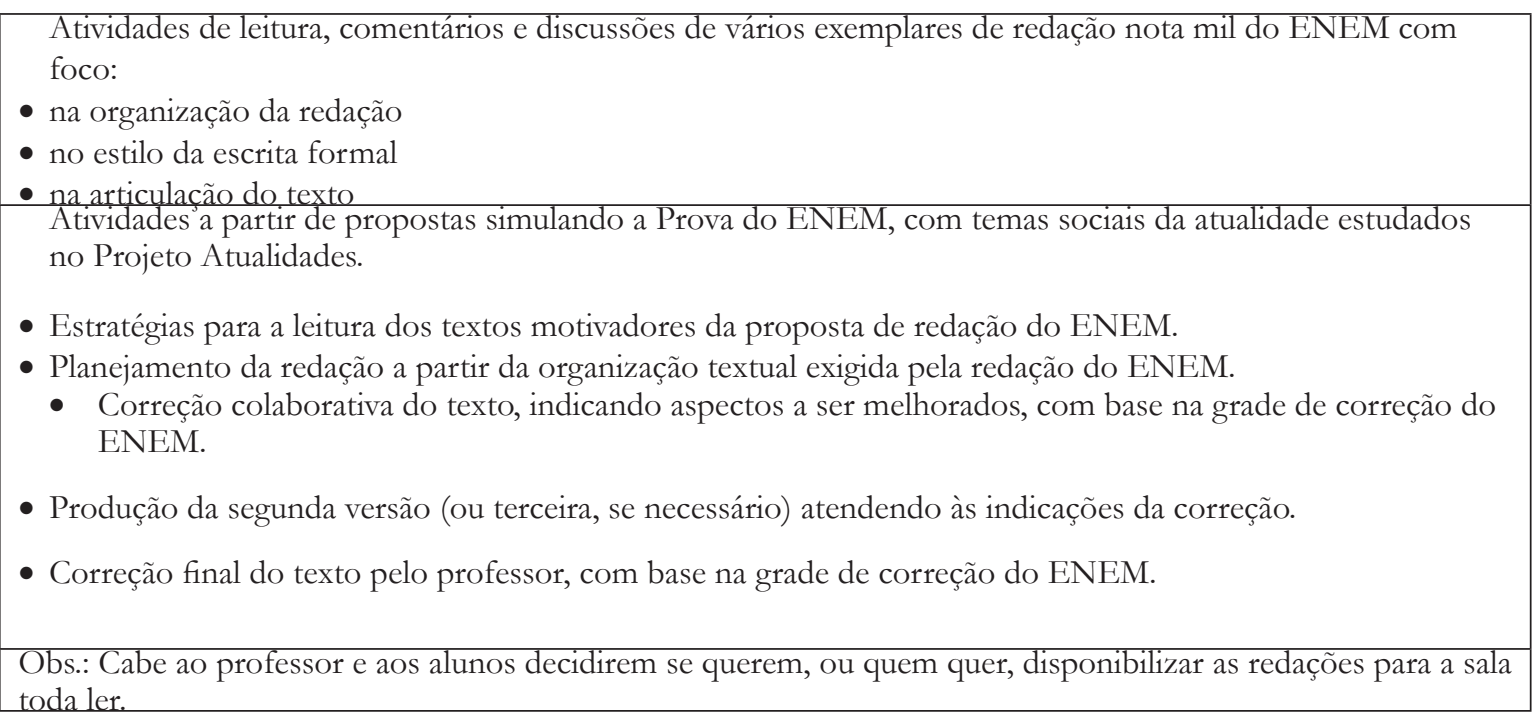

Fonte: A própria autora. 
De acordo com as orientações da Cartilha do Participante do ENEM 2019, especificamente na competência 2, o estudante precisa ser capaz de compreender a proposta de redação, aplicar conceitos das várias áreas de conhecimento para desenvolver o tema, dentro dos limites estruturais do texto dissertativoargumentativo, ou seja, expor seus conhecimentos sobre o tema, apresentar argumentos para defendê-los e apresentar uma proposta de intervenção que respeite os direitos humanos.

Esse manual observa que "Será atribuída nota 0 (zero) à redação que não obedecer à estrutura" (BRASIL, 2019, p. 16). Por isso, nesta pesquisa, são propostas as Atividades de leitura, comentários e discussões de vários exemplares de redação nota mil do ENEM com foco: na organização da redação (competências 2 e 3); no estilo da escrita formal (competência I). Esses exemplares estão disponíveis na internet, portanto, são de fácil acesso. O ideal é que os temas dos exemplos a serem estudados com os alunos sejam daqueles temas do ENEM que foram estudados na etapa de pesquisa e apresentações de seminários do Projeto Atualidades.

Com as redações nota mil em mãos, os alunos devem lê-las e usar cores diferentes para marcar e melhor visualizar a estrutura textual, os mecanismos linguísticos necessários para a construção da argumentação, as estratégias argumentativas utilizadas. Para a melhor visualização dessa estrutura e a partir das características do gênero discursivo Redação do ENEM, especialmente a partir dos dois princípios de estruturação recomendados pela Cartilha do Participante do ENEM 2019 (BRASIL, 2019), esta pesquisa propõe o seguinte quadro para guiar o exercício de reconhecimento da estrutura da Redação do ENEM:

Quadro 3: Organização estrutural do gênero discursivo redação do ENEM

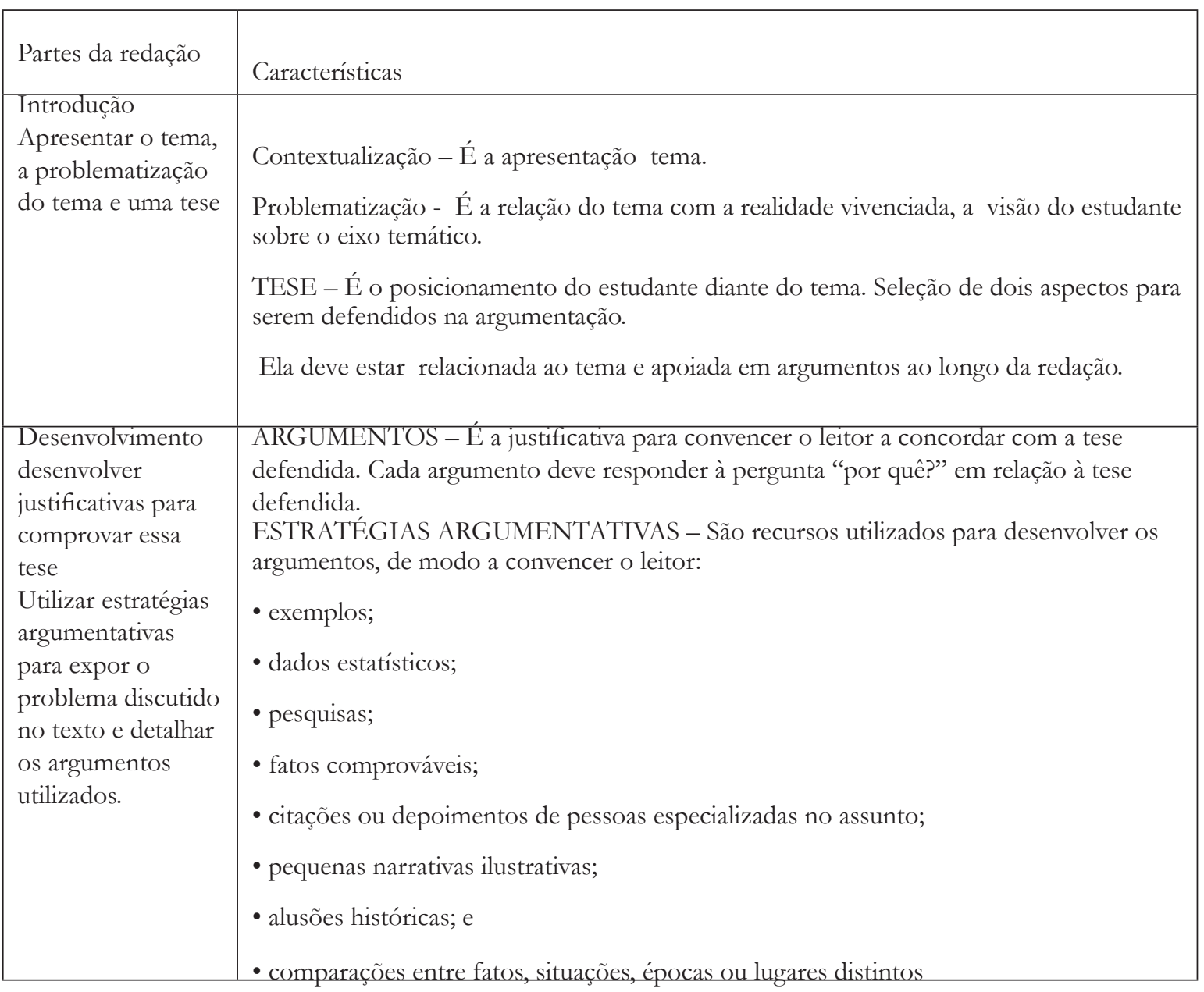




\begin{tabular}{|l|l|}
\hline Conclusão & Retomada da tese apresentada na introdução e elaboração da proposta de intervenção \\
Apresentar uma & social composta por quatro elementos (agente, ação, modo e efeito/finalidade) e \\
proposta de & detalhamento final. \\
intervenção social & \\
que seja inovadora, \\
realizável e que \\
respeite aos \\
direitos humanos.
\end{tabular}

Fonte: A própria autora.

Outra sugestão, ainda para o exercício de alunos algumas estratégias para a leitura dos textos reconhecimento da estrutura da Redação do motivadores das propostas de redação do ENEM, ENEM, é o professor selecionar redações nota mil, imprimi-las, recortá-las de acordo com suas partes e entregar os recortes aos alunos para que eles montem o texto. É um jogo de quebra-cabeças que só poderá ser montado, se fizerem uma leitura atenta e relacionarem os conteúdos de cada recorte com o que se espera de cada parte.

Para as produções escritas dos alunos, as atividades devem partir de propostas simulando a Prova do ENEM. O professor deve elaborar as propostas a partir de temas apresentados no Projeto Atualidades, na forma de enunciado modelo ENEM:

TEXTOS MOTIVADORES (3 ou 4 textos, obtidos na internet, por meio de palavraschave relacionadas ao tema. Podem ser reportagens, infográficos, imagens e textos de toda natureza). A seguir, mostra-se um exemplo do enunciado que compõe a proposta de redação, modelo ENEM.

"A partir da leitura do texto motivador seguinte e com base nos conhecimentos construídos ao longo de sua formação, redija texto dissertativo-argumentativo na modalidade escrita formal da língua portuguesa sobre o tema: a "Manipulação do comportamento do usuário pelo controle de dados na internet," apresentando proposta de intervenção, que respeite os direitos

humanos. Selecione, organize e relacione, de forma coerente e coesa, argumentos e fatos para defesa de seu ponto de vista". Cartilha do Participante do ENEM (BRASIL, 2019, p.14).

Para o sucesso da produção escrita do gênero mencionado, é preciso praticar com os tais como: 1. compreender a proposta de redação e relacioná-la a outras áreas de conhecimento; 2. atentar-se ao que se pede no enunciado; 3. identificar as palavras chaves do tema; 4. fazer perguntas ao tema, relacionando-o à realidade. Com relação aos textos motivadores, os alunos devem: 1 . ler e destacar trechos, relacionando-os com o tema e com outros conhecimentos socioculturais; 2. grifar ideias principais; 3. relacionar informações a fatos da atualidade ou acontecimentos históricos; 4. usar as informações na elaboração de mapa mental ou esquema em que fiquem claras as ideias principais de cada um dos textos motivadores.

Sabe-se que o planejamento da redação do ENEM, na hora do Exame, se dá em um contexto de algumas horas apenas, em que o estudante tem que contar apenas com a memória do que estudou sobre todos os elementos necessários para a produção dessa redação. Por esse motivo, o projeto sugerido nesta pesquisa propõe o uso do quadro 4 , que se apresenta como uma ficha com o esquema geral da redação do ENEM, ou seja, o projeto de texto, apresentado na Cartilha do Participante do ENEM (BRASIL, 2019), especificamente, quando se trata da Competência III. É o momento de relembrar o esquema da organização estrutural do gênero discursivo redação do ENEM, com os itens na coluna da esquerda, e de esquematizar o texto, na coluna da direita. Desta forma, com a prática de várias produções, os alunos se apropriam das características composicionais do gênero. 
Quadro 4: Ficha para planejamento da redação do ENEM

\begin{tabular}{|l|l|}
\hline Partes da redação & Esquematizar em tópicos para depois desenvolver o texto em parágrafos \\
\hline $\begin{array}{l}\text { Introdução } \\
\text { Apresentar o tema, a } \\
\text { problematização do tema e uma } \\
\text { tese }\end{array}$ & (espaço para o esquema elaborado pelo aluno) \\
\hline $\begin{array}{l}\text { Desenvolvimento } \\
\text { Elaborar argumentos em defesa da } \\
\text { tese apresentada; } \\
\text { Utilizar estratégias argumentativas } \\
\text { fundamentadas para comprovar o } \\
\text { problema discutido no texto. }\end{array}$ & \\
\hline $\begin{array}{l}\text { Conclusão } \\
\text { Apresentar uma proposta de } \\
\text { intervenção social que seja } \\
\text { inovadora, realizável e que respeite } \\
\text { aos direitos humanos. }\end{array}$ & \\
\hline
\end{tabular}

Fonte: A própria autora.

Como esta pesquisa assume a produção ou períodos, e o corrige no próprio texto) e a escrita como um processo, com várias etapas, o projeto de preparação dos alunos precisa considerar as etapas finais de:

- Correção colaborativa do texto, indicando aspectos a serem melhorados, com base na grade de correção do ENEM.

- Produção da segunda versão (ou terceira, se necessário) atendendo às indicações da correção.

- Correção final do texto pelo professor, com base na grade de correção do ENEM, com a estimativa de que nota o aluno obteria.

Menegassi e Gasparotto (2019), embasados na concepção bakhtiniana, tratam a escrita como trabalho, no qual o ato de escrever e reescrever são considerados como dois aspectos da mesma atividade. Segundo os autores, a escrita é vista como um processo que apresenta etapas que vão desde o planejamento até a última versão de reescrita, em que se pressupõem a interação, revisão e reescrita. Ademais, pode-se observar que os autores apontam três estratégias de correção textual: a correção indicativa (o professor aponta problemas, sem oferecer aos estudantes, orientações para uma reescrita adequada); a correção resolutiva (o professor observa a ocorrência do erro, em palavras correção classificatória (o professor detecta o erro por meio de uma classificação, a qual possibilita ao estudante a oportunidade da autocorreção). Para uma correção em que se valorizam as relações dialógicas, os autores sugerem a última estratégia. Assim, a reescrita é entendida como uma atitude responsiva do autor diante da revisão do outroleitor. Como esclarecem os autores, todos os aspectos constitutivos do gênero e possibilidades de aprimoramento do desenvolvimento do tema devem ser contemplados.

No caso de um projeto de preparação dos alunos para a redação do ENEM, é preciso classificar e apontar os problemas com base nas características do gênero discursivo redação do ENEM, tendo em mente as competências básicas cobradas na correção dessa prova, já mencionadas no início desta seção. A primeira competência domínio da modalidade escrita formal da língua portuguesa - abrange aspectos linguístico-textuais materializados no texto, especialmente os referentes a regras da gramática normativa e à seleção lexical. A segunda competência - compreensão da proposta de redação e desenvolvimento do tema, dentro dos limites estruturais do texto dissertativo- 
argumentativo em prosa - mobiliza habilidades de leitura da proposta de redação e repertório sociocultural dos alunos para a abordagem do tema e conhecimento da organização textual do gênero redação do ENEM.

As atividades de leitura, comentários e discussões de vários exemplares de redação nota mil do ENEM e as atividades a partir de propostas simulando a Prova do ENEM, com temas de cunho social estudados no Projeto Atualidades sugeridas no Quadro 2 contribuem para o desenvolvimento dessa competência. Além disso, tais atividades ajudam também na aquisição da terceira competência, a qual exige selecionar, relacionar, organizar e interpretar informações, fatos, opiniões com argumentos em defesa de um ponto de vista. Tanto a análise de redações nota mil quanto a correção classificatória, na etapa de revisão e reescrita, contribuem para o desenvolvimento da quarta competência, referente aos mecanismos linguísticos necessários para a construção da argumentação. Por fim, a quinta competência, relativa à proposta de intervenção para o problema abordado que respeite os direitos humanos, resulta da capacidade dos alunos estabelecerem relações dialógicas com o tema, a partir da mobilização de seu repertório sociocultural.

\section{Considerações finais}

Esta pesquisa visou a contribuir para a prática de muitos professores de Língua Portuguesa, que como eu, buscam subsídios para o trabalho de preparação dos alunos para a redação do ENEM. As competências esperadas para que esses alunos sejam bem sucedidos nesse teste não se desenvolvem em práticas rápidas e isoladas. $\mathrm{O}$ levantamento bibliográfico empreendido nesta pesquisa e a análise qualitativa a que foi submetido o material, com vistas também a contemplar as competências 2, 3 e 5 exigidas pela Cartilha do
Participante do ENEM 2019 (BRASIL, 2019), resultou em uma proposta de trabalho que se inicia com o que se denominou Projeto Atualidades. Essa é uma etapa de suma importância porque visa à ampliação de conhecimentos socioculturais dos alunos, essenciais à compreensão da proposta de redação, ao desenvolvimento do tema, por meio da produção textual e à proposição de intervenção que respeite a ética e os direitos humanos. Assim, o conhecimento de temas de cunho social já solicitados pela redação do ENEM, a pesquisa, a discussão e exposição sobre outros potenciais temas da atualidade, o estabelecimento de relações dialógicas entre eles e o momento sócio-histórico atual preparam o estudante para dialogar com a temática da prova.

O referido Projeto Atualidades se organiza por meio de práticas de leitura fundamentadas no estabelecimento de objetivos, no acionamento de conhecimentos prévios dos alunos, na atenção a informações dos textos e na produção de compreensão inferencial. Tais práticas, por serem baseadas nos princípios da abordagem sociocognitiva de leitura, contribuem para a formação de um leitor mais proficiente.

$\mathrm{Na}$ sequência da preparação para a redação do ENEM, em consonância com a fundamentação teórica, a proposta desta pesquisa se completa com práticas de produção escrita a partir de temas estudados e discutidos pelos alunos, planejamento baseado nas características do gênero discursivo redação do ENEM, particularmente os limites estruturais do texto dissertativo-argumentativo em prosa exigido por essa prova, e correção colaborativa e dialógica do professor.

Assim, espera-se que esta proposta possa oferecer uma contribuição aos estudos em Linguística Aplicada sobre produção do gênero discursivo redação do ENEM e subsidiar o trabalho, teoricamente bem fundamentado, dos professores que pretender preparar seus alunos 
para essa prova. Para além dos limites do ENEM, espera-se que os estudantes do Ensino Médio, que vivenciarem as atividades didáticas propostas nesta pesquisa, possam ampliar suas capacidades de leitura, de produção escrita e de estabelecimento de relações dialógicas nos demais contextos de uso da linguagem.

\section{Referências}

BAKHTIN, M. Estética da criação verbal. Trad. Paulo Bezerra. 4.ed. São Paulo: Martins Fontes, 2011.

BARBOSA, J., P., ROVAY, C. F. Gêneros do discurso na escola: Rediscutindo princípios e práticas. São Paulo: FTD, 2012.

BRASIL. Ministério da Educação; Secretaria de Educação Básica. Base Nacional Comum Curricular (BNCC). Brasília: MEC; SEB, 2018. Disponível em: http://basenacionalcomum.mec.gov.br/ images/BNCC_EI_EF_110518_versaofinal_site. pdf. Acesso em: 30 abr. 2019.

BRASIL. Ministério da Educação; Instituto Nacional de Estudos e Pesquisas Educacionais Anísio Teixeira - INEP; Diretoria da Educação Básica - DAEB. Redação do ENEM 2019: Cartilha do participante. Brasília: MEC, 2019. Disponível em:

https://download.inep.gov.br/educacao_basica/ enem/downloads/2019/redacao_enem2019_ cartilha_participante.pdf. Acesso em: 27 out. 2020.

BUNZEN, C. Da era da composição à era dos gêneros: o ensino de produção de textos no Ensino Médio. Português no Ensino Médio e formação do professor. São Paulo: Parábola Editora, 2006.

COSCARELLI, C. V. Reflexões sobre as inferências. Anais do VI CBLA - Congresso Brasileiro de Linguística Aplicada, Faculdade de Letras da UFMG, CD Rom, 2002.

GIL, A. C. Como elaborar projetos de pesquisa. 5. ed. São Paulo: Atlas, 2010.

KOCH, I.; ELIAS, V. M. Escrever e argumentar. São Paulo: Contexto 2017.

LAKATOS, E. M.; MARCONI, M. de A. Fundamentos da Metodologia Científica. 3.ed.rev. e ampl. São Paulo: Atlas, 1991.

LOPES-ROSSI, M. A. G. A produção escrita de gêneros discursivos em sala de aula: aspectos teóricos e sequência didática. SIGNUM: Estudos da Linguagem, Londrina, n. 15, v.3 (Especial), p. 223-245, dez. 2012. Disponível em: http://www.uel.br/revistas/uel/index. php/signum. Acesso em: 10 abr. 2019. LOPES-ROSSI, M. A. G. Sequência didática para leitura de reportagem. In: BARROS, E. M. D. de; STRIQUER, M. dos S. D.; STORTO, L. J. (org.). Propostas didáticas para o ensino da Língua Portuguesa. Campinas: Pontes, 2018, v. 1, p. 71-90.

MARCUSCHI, L. A. Exercícios de compreensão ou copiação nos manuais de ensino de língua? In: LAJOLO, Marisa. (org.). Em Aberto. Brasília, ano 16, n. 69, jan./mar. 1996.

MARCUSCHI, L. A. Leitura como processo inferencial num universo cultural-cognitivo. In: BARZOTTO, Valdir H. (org.). Estado de leitura. Campinas: Mercado de Letras, 1999.

MENEGASSI, R.J; GASPAROTTO, D. M. Revisão dialógica: princípios teórico-metodológicos. Linguagem em (Dis)curso - LemD, Tubarão, SC, v. 19, n. 1, p. 107-124, jan./abr. 2019. Disponível em file:// C:/Users/Eu/Downloads/6596-19041-1PB.pdf. Acesso em 05 abr. 2020.

OLIVEIRA, I. F. de A. Subsídios para o trabalho com o gênero discursivo redação do ENEM. Dissertação (Mestrado em Linguística Aplicada) Universidade de Taubaté, Taubaté, 2020.

PAUlinelli, M. de P. T.; FORTUNATO, G. C. A redação do ENEM à luz dos gêneros discursivos e textuais. RevLet - Revista Virtual de Letras, v. 08, $n^{\circ}$ 01, jan/jul, 2016 ISSN: 2176-9125. Disponível em: http://www.revlet.com.br/artigos/367.pdf. Acesso em: 05 ago. 2018. 
PRADO, D. F. de; MORATO, R. A. A redação do ENEM como gênero textual-discursivo: uma breve reflexão. Cadernos CESPUC de pesquisa. Série Ensaios, n. 29, 2016. Disponível em: http://periodicos.pucminas.br/index. php/cadernoscespuc/article/view/P23583231.2016n29p205/11257. Acesso em: 27 abr. 2019.

ROJO, R.; ALMEIDA, E. de M. (org.). Pedagogia dos multiletramentos. Multiletramentos na escola. São Paulo: Parábola Editorial, 2012.

SOLÉ, I. Estratégias de leitura. 6. ed. Porto Alegre: Artmed, 1996.

VARGAS, D. da S. Por uma visão cognitivista do processo de inferenciação em leitura. Ciências \& Cognição, v. 20, n. 2, p. 313-330, 2015. <Disponível em: http://www.cienciasecognicao.org $>$. Acesso em: 02 fev. 2020.

Submissão: agosto de 2020.

Aceite: dezembro de 2020. 